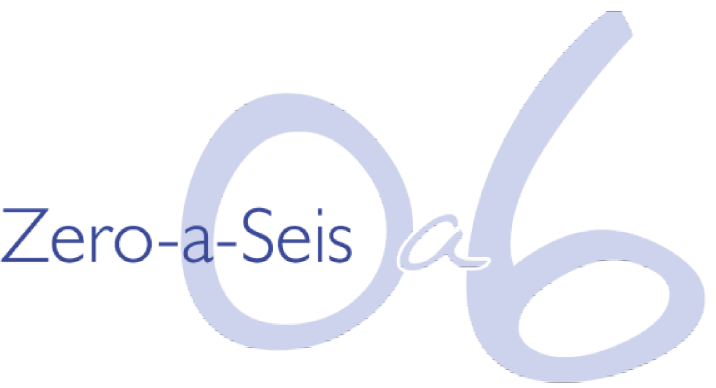

\title{
ESTEREOTIPOS DE GÉNERO EN EDUCACIÓN INFANTIL: UN ESTUDIO DE CASO DESDE LA PERSPECTIVA SOCIOCULTURAL
}

Estereótipos de gênero na Educação Infantil: um estudo de caso a partir da perspectiva sociocultural Gender stereotypes in Childhood Education: a case study from the sociocultural perspective

\author{
Itziar GARCÍA-PRIETO \\ Departamento de Dirección de Empresas y Sociología \\ Universidad de Extremadura, Cáceres, España \\ igprieto@unex.es \\ https://orcid.org/0000-0001-8990-7829 (10)
}

\author{
Rubén ARRIAZU-MUÑOZ \\ Departamento de Dirección de Empresas y Sociología, \\ Universidad de Extremadura, Cáceres, España, \\ rarriazu@unex.es \\ https://orcid.org/0000-0001-6721-6023
}

Mais informações da obra no final do artigo

\section{RESUMEN}

Los estereotipos de género son un estigma sociocultural que se transmiten de generación en generación desde edades muy tempranas. El objetivo de esta investigación es analizar en qué medida inciden los estereotipos de género en la educación infantil. Para abordar esta tarea partimos de un diseño multimétodo concretado en un estudio de caso en el CEI Maracas del que forman parte 15 alumnas/os de entre 3 y 7 años de edad. Las técnicas de recogida de información se basan en la observación directa y sistematizada de cuatro herramientas de carácter cualitativo mediante la triangulación de sus datos. Uno de los resultados más relevantes de esta investigación pone de manifiesto la función efectiva que cumplen los estereotipos de género en la etapa infantil a la hora de iniciarse en el juego. En este sentido, se puede afirmar que las atribuciones estereotipadas de género en niños y niñas están muy presentes en el aula infantil analizada, especialmente, en los mayores de tres años.

PALABRAS CLAVE: Educación; Infanciaํㅜ ; Estereotipo sexual; Investigación social; Problema social.

\section{RESUMO}

Os estereótipos de gênero são um estigma sociocultural que é transmitido de geração em geração desde a mais tenra idade. O objetivo desta investigação é analisar em que medida os estereótipos de gênero afetam a educação na primeira infância. A fim de enfrentar esta tarefa, começamos com um projeto multimétodo que foi concretizado em um estudo de caso no CEI Maracas que inclui 15 crianças entre 3 e 7 anos de idade. As técnicas de coleta de dados baseiam-se na observação direta e sistematizada de quatro ferramentas qualitativas, triangulando seus dados. Um dos resultados mais relevantes desta investigação mostra o papel eficaz desempenhado pelos estereótipos de gênero na fase da infância quando se começa a jogar. Nesse sentido, pode-se afirmar que as atribuições estereotipadas de gênero em meninos e meninas estão muito presentes na sala das crianças analisadas, especialmente naquelas com mais de três anos de idade.

PALAVRAS-CHAVE: Educação; Infância; Estereótipo sexual; Investigação social; Problema social.

$1 *$ Infancia: etapa de la vida comprendida entre el nacimiento y los 6-7 años. Niñez: etapa de la vida que va desde el nacimiento hasta la pubertad, persona que no es adulta. 


\section{ABSTRACT}

Gender stereotypes are a sociocultural stigma that are transmitted from generation to generation from very early ages. The aim of this research is to analyses the extent to which gender stereotypes affect early childhood education. In order to tackle this task, we started with a multi-method design that was concretized in a case study in the CEI Maracas, which includes 15 students between 3 and 7 years old. The techniques for collecting information are based on the direct and systematized observation of four qualitative tools through the triangulation of their data. One of the most relevant results of this research shows the effective role played by gender stereotypes in the infancy stage when starting to play. In this sense, it can be affirmed that the stereotyped attributions of gender in boys and girls are very present in the children's classroom analyzed, especially in those over three years old.

KEYWORDS: Education; Childhood; Gender stereotypes; Social research; Social problems.

\section{INTRODUCCIÓN}

Existe una creciente preocupación por la situación y el lugar que ocupa la mujer en la sociedad actual. Tradicionalmente, la cultura hegemónica y dominante ha atribuido una posición de inferioridad y sometimiento a la mujer y al género femenino asociándolos con roles relacionados con la familia y el cuidado (BONILLA, 1998; MAGALLÓN, 2008; GARCÍA PERALES, 2012). Estas imágenes preconcebidas cargadas de significancia social son lo que conocemos como estereotipos de género. Es una práctica que se van transmitiendo de generación en generación por hombres y mujeres, de mayores a pequeñas/os, de forma consciente o inconsciente y que fundamenta parte de lo que Bourdieu y Passeron (1970) expusieron en su teoría de la reproducción social y cultural. Este planteamiento, un tanto reduccionista pero efectivo, es cuestionado por Giroux (1985) afirmando que el proceso de transmisión cultural no es tan sistemático, sino que dentro de una cultura existen mecanismos desafiantes que cuestionan $y$ transforman los elementos de dominación de una cultura que viene impuesta. En el tema que nos ocupa, la transformación de los estereotipos de género se ha materializado en la lucha de diferentes movimientos sociales por reivindicar un protagonismo más igualitario de la mujer en la sociedad actual.

Los estereotipos sociales de género dependen de la normatividad cultural que es la que delimita "los comportamientos, las características e incluso los pensamientos y emociones que son adecuados para cada ser humano" según su sexo (ROCHASÁNCHEZ, DÍAZ-LOVING, 2005, p. 42). Para intentar alcanzar una igualdad real entre hombres y mujeres, como maestras y maestros, tenemos la responsabilidad de educar a los niños y niñas en la igualdad de género y tomar conciencia de la importancia que tiene la reproducción de los estereotipos de género en la sociedad actual. La presente 
investigación pretende aportar evidencias sobre la huella que los estereotipos de género pueden dejar en las y los más pequeños. En particular, este estudio analiza la influencia de los estereotipos de género en un centro de educación infantil ubicado en un entorno rural de Cáceres. Concretamente, se parte de un diseño multimétodo articulado a través de cuatro técnicas de recogida de la información de carácter cualitativo que tratan de dar respuesta a los objetivos de la investigación. Los resultados dejan patente que desde muy pequeños/as tanto niños como niñas comienzan a reproducir los patrones culturales relativos a los estereotipos de género desde edades muy tempranas.

\section{MARCO TEÓRICO}

La contextualización teórica de los estereotipos de género nos obliga a establecer una aclaración conceptual de partida entre la perspectiva biologicista y la perspectiva cultural que se concreta en la diferencia entre el sexo y el género. Una definición básica de sexo la dan Chandía, Nazar y Oviedo (2014), según la cual el sexo es una característica inherente que presenta condiciones fisiológicas, biológicas y anatómicas donde los hombres están preparados para fecundar y las mujeres para concebir. FaustoSterling (2006) matiza esta definición señalando que el sexo no solo viene definido por la propia genética o la biología, sino que también influye el sentimiento de pertenencia de la persona a un sexo u otro. Las opciones no son solo hombre o mujer, sino que existen, además, diferentes grados de hermafroditismo no contemplados en la primera acepción. Según afirma Weeks (1998), las formas sexuales también serían una construcción social, dependiendo de la concepción cultural que tengan del sexo. Todas las sociedades tienen la necesidad de "reglamentar el sexo" (p. 67) en base a: "parentesco y sistemas familiares, organización social y económica, reglamentación social, intervenciones políticas y el desarrollo de "culturas de resistencia" (WEEKS, 1998, p. 66).

El género por su parte, es una creación sociocultural donde, generalmente, se le impone la feminidad al cuerpo de la mujer y la masculinidad al cuerpo del hombre (FONSECA, QUINTERO, 2009). Los seres humanos no nacemos biológicamente programados para comportarnos de cierta manera por el hecho de ser mujer, ni a pensar de otra forma por ser hombre, sino que es la cultura de una sociedad la que va moldeando la normatividad, los estereotipos, los roles y el estatus atribuidos a mujeres 
y hombres. En términos definitorios, los estereotipos de género son imágenes sociales donde la posición social de cada género es el resultado del sincretismo tradicional de una cultura patriarcal hegemónica y dominante frente a un movimiento social que lucha por revertir esta situación de dominación. Sánchez-Castilla (2001, p. 6) aporta una definición de estereotipo de género muy clarificadora:

[...] Un instrumento creado por las sociedades sexistas y patriarcales con el objeto de marcar unos patrones de comportamiento diferenciados atendiendo al sexo de las personas. De esta manera se les atribuye a hombres y mujeres un papel social, político, económico y cultural diferente, provocando una dicotomía que causa estructuras asimétricas y desiguales. (SÁNCHEZ-CASTILLA, 2001, p. 6)

Profundizando en esta cuestión, las cualidades asignadas generalmente al género masculino se consideran superiores a las asignadas al género femenino. Por ejemplo, tradicionalmente las cualidades estereotipadas como masculinas son el "poder, propiedad y potencia" (LEMUS, 2007) fuerza, competitividad e inteligencia y las cualidades estereotipadas como femeninas serían la "subordinación, entrega, pasividad y seducción [...]" (PLA, ADAM Y BERNABEU, 2013, p. 23) ternura, intuición y colaboración (ARTAL, 2009).

Teniendo en cuenta este condicionamiento sociocultural, la pregunta sería: ¿Cómo se construyen los estereotipos de género? Existen diferentes aproximaciones teóricas que García-Leiva (2005, p. 72) divide en tres grandes grupos: "Socio-biológicas, Constructivismo Social y Psicodinámicas". En esta investigación adoptamos un posicionamiento teórico basado en el Constructivismo Social donde la definición de los estereotipos de género son entendidos como una construcción social que le viene dada a la persona desde su cultura de partida, es decir, el individuo desde su propio nacimiento es sometido a diferentes procesos de socialización cargados de mensajes estereotipados donde la identidad y los estereotipos de género se van modulando siguiendo una normatividad socialmente aceptada. Pensemos, por ejemplo, en el color de la ropa que eligen unos padres, los elementos que se emplean para decorar el cuarto de un recién nacido o el tipo de juguetes que se suele regalar a un niño y a una niña y estaremos presenciando esa consolidación cultural aparentemente neutra pero explícitamente cargada de significados sociales.

La perspectiva teórica constructivista se apoya en los postulados de la teoría Queer definida por Judith Butler. Esta teoría expone que el género se construye mediante la representación y reproducción de roles de género preestablecidos, a lo que 
Butler llama "performatividad teatral"2 (BUTLER, 2007). Teóricamente, solo existen dos géneros (femenino y masculino), por lo que una persona no es completamente libre para expresar su propio género. De este modo, esta teoría niega que exista una relación causal entre el sexo y el género. En la construcción del género influyen principalmente dos aspectos, según Gros (2016): la estructura social (la cual impone la heterosexualidad obligatoria) y la acción social sobre la persona (que incluye los gestos, la vestimenta, el lenguaje...).

Otro de los enclaves teóricos importantes en el análisis de los estereotipos de género desde el constructivismo es la propia interacción social. En este sentido, las aportaciones del interaccionismo simbólico son esenciales para entender los procesos de conformación y reafirmación del estereotipo. El planteamiento básico de esta teórica postula que la realidad se construye a través de las relaciones entre el individuo y la sociedad. Martínez (2015), basándose en las aportaciones de Blumer, explica que las personas, a medida que interaccionan con el medio que les rodea, van produciendo una serie de significados y símbolos que sustituyen a los objetos reales a los que se refieren, conformándose así su realidad social. Además de estas interacciones, debe tenerse en cuenta la interpretación que el individuo realiza sobre ello (CARABAÑA Y ESPINOSA, 1978). Así, la formación de estereotipos de género (o los símbolos en relación al género) se lleva a cabo a través de las relaciones con los demás, las situaciones en que se interactúa, las estructuras jerárquicas de la interacción, los símbolos que se crean, las interpretaciones que se realizan y los significados que se le atribuyen a esas interacciones con otras personas y con el medio social.

Las múltiples dimensiones de análisis que abarcan los estereotipos de género desde la perspectiva constructivista nos conducen también a considerar un abordaje holístico e interdependiente a través de la teoría sistémica. Esta teoría sociocultural organiza la sociedad y agrupa a los individuos en sistemas de representación básicos para la persona, es decir, un individuo puede pertenecer a varios sistemas sociales diferentes en el que los estereotipos de género están presentes con mayor o menor incidencia: familia, colegio, grupo de amigos... Todos los sistemas influyen sobre el individuo, siendo más preponderantes los sistemas o subsistemas con los que se tenga una relación o vínculo más estrecho. El sistema familia es uno de los más importantes

\footnotetext{
2 Performatividad teatral: reproducir/representar/expresar un rol de género como si fuera el papel de un actor en una película. Es decir, con unas pautas ya marcadas por la sociedad.
} 
ya que los individuos empiecen a conformar su identidad y personalidad (ANDRADE Y ARBOLEDA, 2001) y donde se asientan los primeros estereotipos de género.

Por último, y siguiendo esta línea sociocultural para definir el abordaje teórico de los estereotipos de género, resultan básicas las aportaciones del modelo ecológico de Bronfenbrenner. "La perspectiva ecológica surge como un intento de integrar tres niveles de análisis: el individuo, el nivel socio-psicológico y el nivel socio-cultural" (Toldo, 2002, p. 48). Este modelo permite agrupar los diferentes escenarios sociales "que afectan directa o indirectamente al desarrollo de las personas" (MARTÍNEZ, ROBLES, UTRIA, AMAR, 2014, p. 138): microsistema (por ejemplo, relación individuofamilia), mesosistema (por ejemplo, relación familia-escuela), exosistema (por ejemplo, medios de comunicación) y macrosistema (cultura) (FRÍAS-ARMENTA, LÓPEZESCOBAR, DÍAZ-MÉNDEZ, 2003). Los estereotipos de género pueden surgir de las interacciones que el individuo realice en cada uno de estos ambientes y del tipo de feedback que reciba, asumiendo en primera persona lo que se considera correcto en términos normativos.

Asumiendo los principales argumentos de las teorías sociales expuestas, y asumiendo también la complejidad sociocultural a la que están expuestos los estereotipos de género, podrá comprenderse que los modelos estereotipados que se generan en los diferentes entornos familiares y grupales se proyecten posteriormente en las aulas de educación infantil, tanto en docentes como en el alumnado. Aunque el currículo educativo establezca políticas de equidad de género, la realidad es que los estereotipos en general, y los estereotipos de género en particular, forman parte del currículo oculto que se genera en el aula. Dicho de otro modo, los estereotipos de género forman parte de la interacción cotidiana del aula. Aparecen concretados en pequeñas cosas, en pequeños detalles tanto del/la profesor/a como de los propios alumnos $/ \mathrm{as}^{3}$ y progresivamente se asumen como algo normal y certero. Por ejemplo, es un hecho socialmente aceptado que en la profesión de maestro/a de educación infantil, predominan las mujeres docentes, lo cual puede ayudar a transmitir determinados estereotipos de género vinculados al cuidado (CAPDEVILLA, VENDRELL, CILLER, BILBAO, 2014; MARTÍNEZ, ORGAZ, VICARIO-MOLINA, GONZÁLEZ, CARCEDO, FERNÁNDEZ-FUENTES, FUENTES, 2011), incluso las maestras justifican este hecho apelando al instinto maternal de las mujeres (Henriques y de Jesus, 2016).

\footnotetext{
${ }^{3}$ La palabra "alumno/a" hace referencia a una persona adscrita a una institución educativa y que es parte activa de su propia educación
} 
La construcción identitaria de la persona comienza alrededor de los dos años (JAYME, 1999) y se produce principalmente dentro de la familia y la escuela (CAPDEVILLA et al, 2014; RODRÍGUEZ, HERNÁNDEZ, PEÑA, 2004). Esto puede observarse fácilmente a través del juego infantil, puesto que es la principal vía de comunicación mediante la cual los niños y niñas plasman sus opiniones, miedos, vivencias y, por supuesto, estereotipos. En la investigación realizada por Rodríguez, Hernández y Peña (2004) se encuentran grandes diferencias en el juego de niños y niñas de educación infantil, como puede observarse en la Tabla 1.

Tabla 1. Diferencias en el juego entre niños y niñas.

\begin{tabular}{|c|c|c|}
\hline Ítem & Niñas & Niños \\
\hline $\begin{array}{l}\text { Tipo de juego } \\
\text { preferente }\end{array}$ & Juegos simbólicos & Deportes (fútbol) \\
\hline Zona de recreo & En la periferia & En el centro del recreo \\
\hline $\begin{array}{l}\text { Juego en los } \\
\text { rincones }\end{array}$ & Casita, peluquería & $\begin{array}{c}\text { Construcciones, } \\
\text { bomberos }\end{array}$ \\
\hline Roles & $\begin{array}{c}\text { Más romántico }{ }^{5} \text { o } \\
\text { maternal (princesas o } \\
\text { madres embarazadas) }\end{array}$ & $\begin{array}{l}\text { No romántico } \\
\text { (Caballeros, no } \\
\text { príncipes) }\end{array}$ \\
\hline $\begin{array}{c}\text { Según edad (de } 3 \text { a } 5 \\
\text { años) }\end{array}$ & $\begin{array}{l}\text { A más edad, se decantan } \\
\text { más por juegos } \\
\text { estereotipados como } \\
\text { femeninos }\end{array}$ & $\begin{array}{c}\text { A mayor edad, se niegan } \\
\text { a jugar a juegos } \\
\text { denominados } \\
\text { "femeninos". Ejercen un } \\
\text { menor rol paternal. }\end{array}$ \\
\hline $\begin{array}{l}\text { Compañeros/as de } \\
\text { juego (con } 3 \text { años el } \\
\text { grupo es más } \\
\text { heterogéneo) }\end{array}$ & $\begin{array}{l}\text { De } 4 \text { a } 5 \text { años, prefieren } \\
\text { hacer grupo con niñas. }\end{array}$ & $\begin{array}{l}\text { A partir de los } 4 \text { años se } \\
\text { comienzan a hacer } \\
\text { grupos solo con niños. }\end{array}$ \\
\hline $\begin{array}{c}\text { Características del } \\
\text { juego }\end{array}$ & $\begin{array}{c}\text { De reglas, de } \\
\text { construcción, más } \\
\text { elaborado, de personajes, } \\
\text { no se tiran por el suelo } \\
\text { tan fácilmente, planean el } \\
\text { juego. }\end{array}$ & $\begin{array}{l}\text { Más brusco e impulsivo, } \\
\text { de destrucción, peleas, } \\
\text { se tiran por el suelo, } \\
\text { actúan sin pensar. }\end{array}$ \\
\hline
\end{tabular}

Tabla 1: Elaboración propia a partir de los datos de Rodríguez et al (2004).

Otra de las investigaciones relevantes sobre los estereotipos de género es la llevada a cabo por Henriques y De Jesus (2016) la cual concluye de la siguiente manera tras las entrevistas mantenidas con niños y niñas de educación infantil: 1) Se reconocen

\footnotetext{
${ }^{4}$ Los "rincones" son una propuesta metodológica para organizar la dinámica del aula. Se divide el aula por zonas temáticas (rincón lógico-matemático, del juego simbólico, de expresión artística, etc.), donde los/las niños/as eligen y juegan libremente durante un tiempo determinado.

${ }^{5}$ El diccionario de la Real Academia Española, en una de sus acepciones, define el concepto de "romántico", como sinónimo de "sentimental, generoso y soñador".
} 
como niños o niñas a partir de características físicas, 2) Asignan diferentes roles a mujeres y a hombres según lo que observan en su casa: a mujeres labores de crianza y tareas del hogar y a hombres el descanso, 3) Niños y niñas muestran preferencias diferentes por los juegos. Los niños prefieren coches, muñecos de superhéroes y juegos de lucha y donde se emplea la fuerza y las niñas prefieren muñecas, carros de muñecas y ropa de color rosa, 4) Se asocia el color azul a los niños y el color rosa a las niñas, 4 ) La mayoría de niños y niñas muestran flexibilidad para cambiar esos estereotipos de género.

Otra investigación destacable es la llevada a cabo por Rodríguez y Torio (2005) en la que se realizaron grupos de discusión con maestras/os de educación infantil. Los resultados más sobresalientes ponen de manifiesto el hecho de que las niñas son las que tienen más actitudes de ayuda hacia otros niños/as y, sobre todo, hacia los más pequeños. Del mismo modo, no se observaron diferencias en el juego de los infantes de 3 años, pero a partir de los 4 años los grupos de juego se van haciendo más homogéneos según el sexo. En definitiva, se van encontrando más diferencias actitudinales cuanto mayor es la edad del alumnado.

En el plano curricular, son importantes también los materiales que se emplean en el aula, se deben evitar aquellos que no enfaticen en la equidad de género. En el estudio de Cabrera y Martínez (2014) sobre las ilustraciones expuestas en dos libros para colorear, Doodles para niños y Doodles para niñas -editorial Michael O Mara Books-', se encuentran diferencias significativas en la reproducción de estereotipos de género. Por ejemplo, en Doodles para niñas, son las niñas y mujeres las mayormente representadas en los dibujos ( $80 \%$ con mujeres/niñas protagonistas, frente al $20 \%$ de hombres protagonistas). En Doodles para niñas, sí existe representación de hombres solos o colectivos de hombres. En los libros para colorear de niños, las mujeres y niñas son escasamente representadas y nunca aparecen solas y/o siendo protagonistas mientras que los hombres son protagonistas en todas las ilustraciones. Del mismo modo, en ambos libros, se muestran temáticas muy diferentes.

Los resultados de las investigaciones recientes llevadas a cabo en materia de estereotipos de género revelan la significatividad y la multidimensionalidad del problema en cuestión. Los estereotipos están arraigados a las prácticas culturales y son percibidos e interiorizados dentro de la práctica cotidiana. Como se ha podido apreciar también, los estereotipos están presentes en multitud de escenarios y en multitud de recursos y agentes educativos. La presente investigación pretende contribuir al análisis 
de este fenómeno sociocultural tomando como punto de partida el estudio de caso de un centro de educación infantil ubicado en un entorno rural de la provincia de Cáceres.

\section{MÉTODO}

La investigación desarrollada se encuadra dentro de un paradigma integrador que aúna la investigación cualitativa y cuantitativa y que se concreta en un diseño de investigación multimétodo. La decisión de utilizar una metodología conjunta tiene como objetivo paliar las debilidades metodológicas de un solo paradigma al tiempo que reportar una mayor consistencia en los resultados de la investigación (BLANCO, PIRELA, 2016; OKUDA, GÓMEZ-RESTREPO, 2005). Dentro de las variantes del diseño multimétodo se ha seleccionado el diseño múltiple (TASHAKKORI Y TEDDLIE, 2003 apoud BLANCO Y PIRELA, 2016, p. 105) cuya estrategia operativa de aplicación es la triangulación de los datos. En este sentido, y siguiendo la propuesta de Bericat (1998), hemos seleccionado la triangulación intratécnica en la que dentro de un mismo método de investigación se emplean diferentes instrumentos de recogida y análisis de la información. La triangulación tiene un carácter fundamentalmente sumativo, es decir, contribuir a la identificación, descripción y explicación de los estereotipos de género que se identifiquen en este grupo de alumnas/os.

Los objetivos de la investigación han sido definidos de manera secuencial tratando de identificar, contextualizar y explicar los estereotipos de género presentes en el alumnado del Centro de Educación Infantil Maracas de la Comunidad de Cáceres. Bajo esta premisa, el objetivo general es observar si existen estereotipos de género en niños y niñas de 3 a 7 años del centro de educación infantil Maracas durante su apertura en el año.

Las categorías de análisis vienen determinadas por los objetivos específicos planteados en el diseño. En concreto, proponemos los siguientes objetivos: 1) Observar si los alumnos y las alumnas tienen actitudes basadas en los estereotipos de género, 2) Examinar si prefieren seleccionar dibujos estereotipados como femeninos/masculinos o neutros, 3) Identificar si realizan comentarios sexistas, 4) Valorar si existen diferencias entre niños y niñas en la ocupación del espacio físico durante el juego libre, 5) Describir qué tipo de juego prefieren los niños y niñas 
asistentes al centro y 6) Señalar los tipos de relaciones vinculadas al género que se establecen en los juegos.

\subsection{Contexto y participantes}

En lo relativo a la Educación Infantil, la normativa vigente en el territorio español está actualmente regulada por la Ley Orgánica 8/2013, de 9 de diciembre, para la Mejora de la Calidad Educativa (LOMCE), que da continuidad a lo aprobado en la Ley Orgánica 2/2006, de 3 de mayo, de Educación (LOE). Esta normativa establece que la Educación Infantil se extiende desde el nacimiento hasta los 6 años, dividida en dos ciclos: primero (0-3 años) y segundo (3-6 años). El centro educativo seleccionado en la investigación es un centro de segundo ciclo de Educación Infantil haciendo una excepción a la normativa por cuestiones de necesidad laboral, admitiendo también a niños y niñas de 7 años. En cuanto a las enseñanzas impartidas, el centro sigue los contenidos aprobados en el Real Decreto 1630/2006, de 29 de diciembre, por el que se establecen las enseñanzas mínimas del segundo ciclo de Educación Infantil, regulando los objetivos, fines y principios generales de la etapa. Por su parte, la autonomía del centro también se encuentra amparada por el régimen autonómico de la Comunidad de Extremadura. Concretamente, el nivel curricular de Educación Infantil se desarrolla sobre el Decreto 4/2008, de 11 de enero, por el que se aprueba el currículo de Educación Infantil para la Comunidad Autónoma de Extremadura (España).

El trabajo de campo se ha llevado a cabo en el Centro de Educación Infantil Maracas, ubicado en el entorno rural de la provincia de Cáceres, dentro de un municipio que censa 200 habitantes. Este centro se abre únicamente durante la temporada de recogida de fruta (de mayo a julio, de lunes a domingo) y en horario de 9:00 a 13:00 de la mañana y de 15:00 a 20:00 de la tarde. Forman parte de la investigación todos/as los/as niños y niñas mayores de 3 años asistentes al centro, un total de 8 niños y niñas de 3 a 7 años. La Tabla 2 muestra su desglose por edad y sexo.

Tabla 2. Desglose por edad y sexo de los/las participantes.

\begin{tabular}{|c|c|c|c|c|c|c|}
\hline S / E & $\mathbf{3}$ años & $\mathbf{4}$ años & $\mathbf{5}$ años & $\mathbf{6}$ años & $\mathbf{7}$ años & Total \\
\hline Niños & 0 & 2 & 1 & 0 & 2 & 5 \\
\hline Niñas & 1 & 0 & 1 & 1 & 0 & 3 \\
\hline Total & 1 & 2 & 2 & 1 & 2 & 8 \\
\hline
\end{tabular}

Fuente: Elaboración propia. 
Las madres y padres que llegan o viven en esta localidad y se dedican a la recogida de la fruta, necesitan dejar a sus hijos e hijas en un lugar seguro mientras ellos/as trabajan, por lo que surge la necesidad de ofrecerles este tipo de centro. Por eso, en el Centro de Educación Infantil Maracas, se encuentran niños y niñas de diferente nacionalidad y se hablan diferentes lenguas. Es un centro con características excepcionales dentro del territorio autonómico y nacional.

\subsection{Instrumentos de recogida de datos}

El método principal para la recogida de la información ha sido la observación directa. En este sentido, seguimos la línea antropológica de la visión Emic donde el rol de la investigadora será también la de "participante-como-observadora" (VALLES, 1999, p. 151). En lo que concierne a los instrumentos para la recogida de datos se ha tratado siempre de mantener el anonimato en el proceso y de minimizar la intrusión de las dinámicas del aula. En este sentido, se han elaborado los siguientes instrumentos de recogida:

- Checklist o lista de cotejo: Documento de carácter dicotómico que contempla un total de 14 indicadores sobre estereotipos de género. Ha servido para registrar la frecuencia actitudinal de las niñas y los niños en clase.

- Ficha de observación de clase: Tabla bidimensional de frecuencia, que ha reflejado las actividades realizadas en el aula por el alumnado en relación con los estereotipos de género, los/las protagonistas de la acción y el lenguaje empleado.

- Ficha de observación del recreo: Tabla bidimensional, donde se ha registrado la actividad realizada por los niños y las niñas participantes en el patio de recreo, el espacio que ocupan y el lenguaje o actitud que emplean, si es relevante para la investigación.

- Registro anecdótico: Documento donde se ha dejado constancia de todas las situaciones, conversaciones y comentarios que se produjeron dentro del aula, relacionados con los estereotipos o la equidad de género.

\subsection{Procedimiento}

Tanto el centro como los/las participantes han sido seleccionados por la buena accesibilidad para su investigación (muestreo no probabilístico, por conveniencia, casual 
o incidental). Inicialmente, y con el propósito de identificar las dinámicas y particularidades del contexto de investigación, se procedió mediante la observación directa no estructurada a fijar las condiciones de posibilidad del aula y delimitar los instrumentos de recogida de información más pertinentes. Una vez realizado este diagnóstico preliminar, se elaboraron los instrumentos de recogida de la información, lo cual permitió sistematizar la observación y registrar el corpus de la investigación. Concretamente, el trabajo de campo tuvo una duración de un mes y medio realizando anotaciones periódicas en 20 días diferentes seleccionados al azar. Una vez recogida toda la información, se procede al análisis de los resultados y a la triangulación de datos a partir de los distintos instrumentos seleccionados.

\section{RESULTADOS}

Los resultados de la investigación ponen de manifiesto la repercusión que tienen los estereotipos de género en los diferentes contextos educativos registrados. Siguiendo la lógica metodológica de la triangulación, y guiándonos por las categorías de análisis fijadas en los objetivos específicos, pasamos a continuación a exponer los resultados según dos grandes categorías: 1) El juego y los estereotipos de género y 2) Las actitudes sexistas. Respecto a la primera categoría de los resultados diferenciamos elementos analíticos como el tipo de juego que prefiere el alumnado según el condicionamiento de los estereotipos de género, las relaciones que se establecen entre compañeros/as en torno al género, la ocupación del espacio que se lleva a cabo en los juegos y la preferencia que muestra el alumnado por un tipo de dibujos u otro según la incidencia del género. Las subcategorías de la segunda parte del estudio examinan las actitudes de cuidado y las narrativas de las actitudes sexistas que se hayan podido identificar

dentro

del

aula.

\subsection{El juego y los estereotipos de género}

Tabla 3. Porcentaje de niños y niñas que han jugado a cada tipo de juego alguna vez.

\begin{tabular}{|c|c|c|c|c|c|c|c|}
\hline & $\begin{array}{c}\text { Muñeca } \\
\text { s }\end{array}$ & $\begin{array}{c}\text { Cocinit } \\
\mathbf{a}\end{array}$ & $\begin{array}{c}\text { Cooperació } \\
\mathbf{n}\end{array}$ & $\begin{array}{c}\text { Cuento } \\
\mathbf{s}\end{array}$ & $\begin{array}{c}\text { Construcció } \\
\mathbf{n}\end{array}$ & $\begin{array}{c}\text { Fuerz } \\
\mathbf{a}\end{array}$ & $\begin{array}{c}\text { Coche } \\
\mathbf{s}\end{array}$ \\
\hline $\begin{array}{c}\text { Niño } \\
\text { s }\end{array}$ & $12,5 \%$ & $75 \%$ & $62,5 \%$ & $75 \%$ & $100 \%$ & $75 \%$ & $87,5 \%$ \\
\hline
\end{tabular}




\begin{tabular}{|c|c|c|c|c|c|c|c|}
\hline $\begin{array}{c}\text { Niña } \\
\text { s }\end{array}$ & $87,5 \%$ & $62,5 \%$ & $37,5 \%$ & $87,5 \%$ & $100 \%$ & $25 \%$ & $25 \%$ \\
\hline
\end{tabular}

Fuente: Elaboración propia.

La dimensión lúdica representa el primer escenario de análisis y al mismo tiempo un espacio muy revelador para observar el papel de los estereotipos sociales en el juego. En este sentido, y siguiendo las aportaciones de investigaciones anteriores, se ha diferenciado entre juegos estereotipados como femeninos (muñecas, cocinita, juegos de cooperación y cuentos) y juegos estereotipados como masculinos (bloques de construcción, juegos de fuerza o competición y coches). La Tabla 3 muestra la distribución lúdica durante el periodo analizado, donde se presenta el porcentaje de niños/as que ha jugado al menos una sola vez al tipo de juego descrito.

Sin ánimo de generalizar, los porcentajes más destacables de la Tabla 3 evidencian la preponderancia de los estereotipos de género en el juego. Concretamente, en las observaciones realizadas, el $87,5 \%$ de niños no ha jugado nunca con las muñecas, el $75 \%$ de los niños ha jugado alguna vez a juegos de fuerza, frente al 25\% de niñas. Así como también destaca el $75 \%$ de las niñas que no han jugado nunca con coches. La mayoría de niños y niñas jugó a las cocinitas y a los juegos de construcción porque fueron juegos novedosos que veían por primera vez, así que todos/as quisieron curiosear al menos una vez en toda la temporada. Descrita la decisión de jugar, otro de los factores a tener en cuenta es la frecuencia de juego que han tenido niños y niñas en estos mismos juegos.

En la Figura 1 se puede apreciar la reafirmación de la elección del tipo de juego, en este caso, mediada por los estereotipos de género. En este sentido, las niñas son las que juegan con una mayor frecuencia a juegos estereotipados como femeninos (las muñecas o los cuentos) frente a los niños que destacan por jugar a juegos estereotipados como masculinos. La relación numérica identificada en la elección de estos juegos se corresponde con determinados fragmentos triangulados con los registros del anecdotario. 


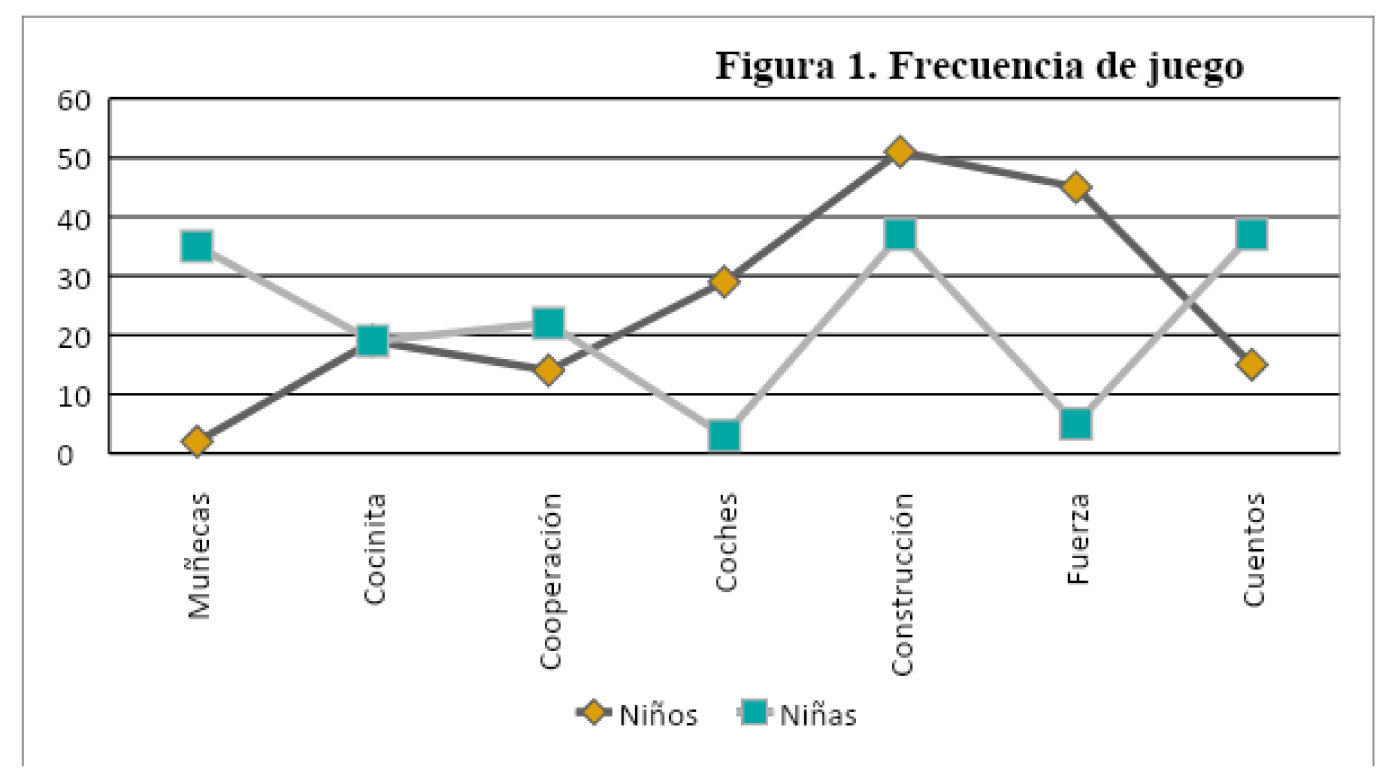

Anecdotario

Fecha: 4 de julio

Mientras Raúl, Fernando y Carlos juegan a lanzarse cosas, tirarse por el suelo, etc., Laura, Lourdes y Regina juegan a las peluquerías, se peinan entre ellas o nos peinan a nosotras. Al principio jugaban más todos/as juntos/as, pero se han ido separando poco a poco.

Esta primera dimensión del análisis es útil para contextualizar y reafirmar la presencia de los estereotipos de género en la etapa infantil en el escenario lúdico. El dato puede no resultar revelador; sin embargo, la pregunta es ¿por qué se constata la elección de juegos estereotipados? No cabe duda que existen una serie de subsistemas sociales de los que se nutre el alumno/a para optar por uno u otro juego. Al no resultar abarcables todos ellos, profundizaremos ahora en la incidencia que ha tenido las relaciones interpersonales en el centro educativo durante el periodo analizado según el tipo de interacción.

La Tabla 4 muestra visualmente el resumen y el tipo de relaciones establecidas entre niño y niña en el periodo analizado. En consonancia con los resultados anteriores, la tabla 4 aporta una nueva evidencia de los estereotipos de género, en este caso, marcada por la diferenciación relacional de los niños/as según la variable sexo. Salvo en casos puntuales, existe una tendencia donde las niñas mayores, por lo general, prefieren relacionarse con las niñas o con los niños más pequeños y los niños prefieren relacionarse con otros niños. El marco relacional reafirma la postura que identificábamos frente a la elección o frecuencia del juego donde la variable sexo genera un efecto divisorio entre las alumnas y alumnos. 
Tabla 4. Datos del ítem 10. Interacciones niño-niña.

\begin{tabular}{|c|c|c|c|c|c|c|c|c|}
\hline & Fernando & Mario & Raúl & Carlos & Nicolae & Luís & Martín & Pablo \\
\hline Laura & + & + & $*$ & $*$ & 0 & + & + & + \\
\hline Lourdes & + & 0 & - & + & 0 & + & + & + \\
\hline Regina & + & $\mathbf{0}$ & $*$ & + & 0 & $*$ & + & $*$ \\
\hline Andrea & + & 0 & 0 & 0 & 0 & + & + & + \\
\hline Marta & + & 0 & 0 & $*$ & 0 & $*$ & $*$ & $*$ \\
\hline Lucía & + & 0 & 0 & 0 & 0 & $*$ & $*$ & $*$ \\
\hline \multirow[t]{2}{*}{ Helena } & + & $\mathbf{0}$ & $\mathbf{0}$ & 0 & + & 0 & 0 & 0 \\
\hline & \multicolumn{8}{|c|}{$\begin{array}{c}\text { Leyenda: + relación positiva; - relación mayormente negativa; } * \text { relación } \\
\text { variable; } 0 \text { relación nula }\end{array}$} \\
\hline
\end{tabular}

Fuente: elaboración propia.

Profundizando ahora en el análisis de los dibujos realizados durante el periodo que engloba el trabajo de campo, se ha tomado como referencia el trabajo de Cabrera y Martínez (2014) y se han dividido los dibujos en tres grandes grupos según los estereotipos de género que en ellos se puedan identificar. En este sentido diferenciamos entre, dibujos estereotipados como femeninos: aquellos en los que aparecen princesas, niñas jugando, flores, personajes famosos femeninos (Campanilla ${ }^{\text {Tm }}$, Hello Kitty ${ }^{\circledR}$, Minnie Mouse $\left.{ }^{\circledast}\right)$; dibujos estereotipados como masculinos: aquellos cuya temática eran deportes, príncipes, dragones, niños jugando, coches, superhéroes; y dibujos no estereotipados o neutros: donde aparecen solo animales, niños y niñas jugando o paisajes naturales. Por norma general, los niños han seleccionado un mayor número de veces dibujos estereotipados como masculinos o neutros y los han coloreado con colores más oscuros como el azul, el negro o el rojo. Las niñas por su parte han seleccionado un mayor número de veces dibujos estereotipados como femeninos o neutros y los han coloreado con colores más claros como el rosa, el naranja o el amarillo, como puede observarse en los siguientes dibujos: 


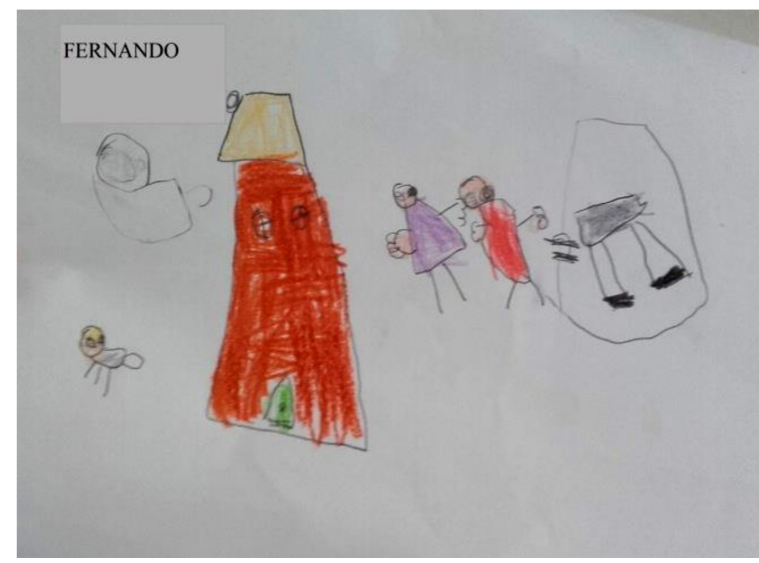

1. Dibujo de un niño y una niña jugando en el parque, de Fernando (6 años)

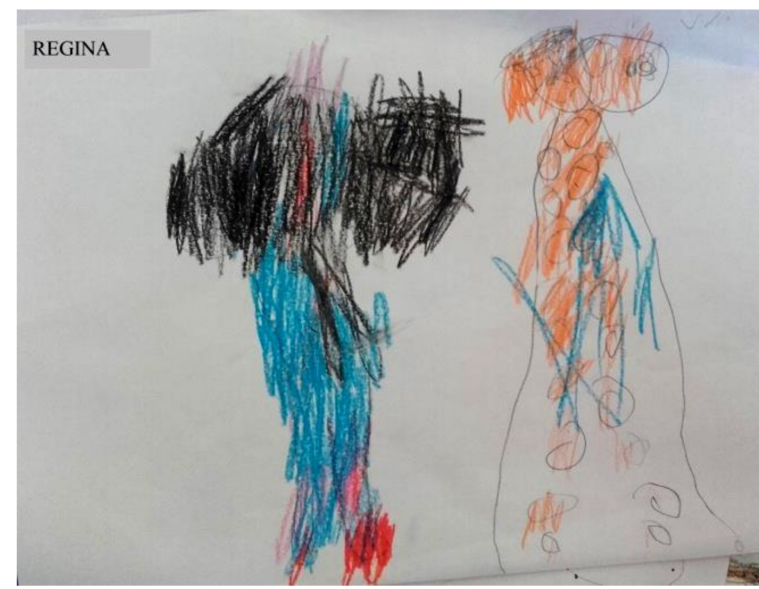

3. Dibujo de un niño y una niña jugando en el parque, de Regina ( 3 años)

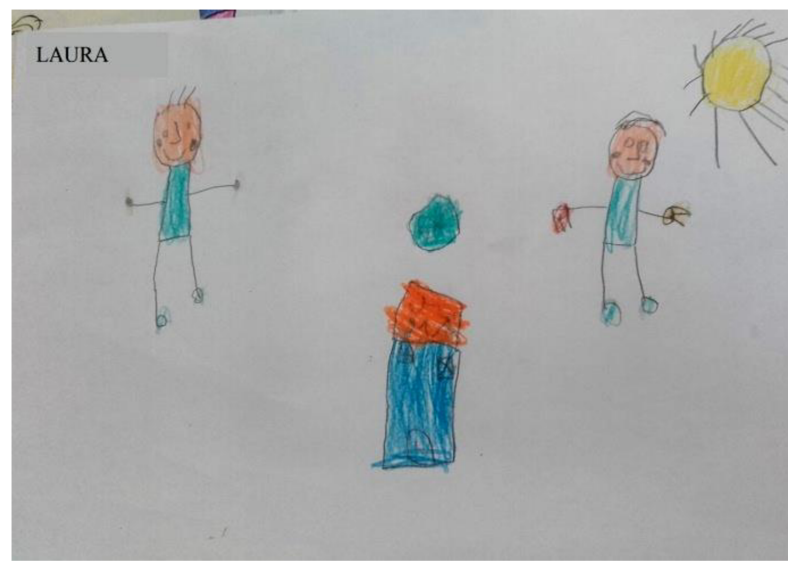

2. Dibujo de un niño y una niña jugando en el parque, de Laura ( 5 años)

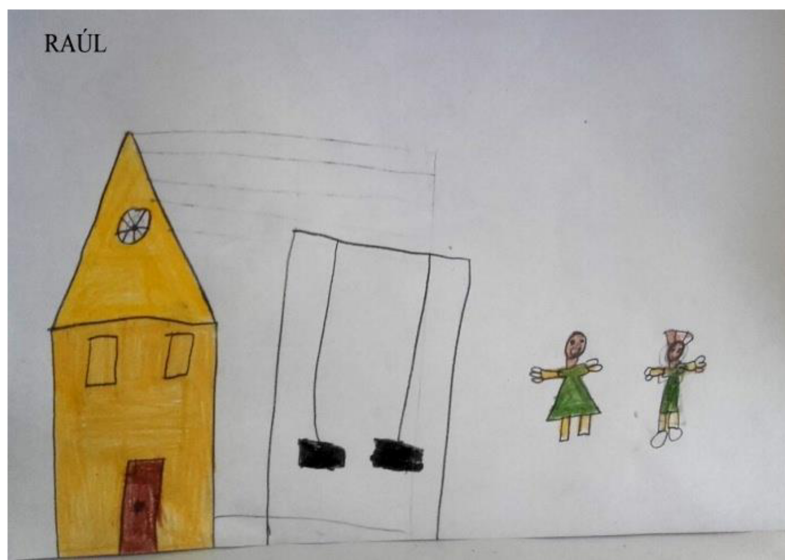

4. Dibujo de un niño y una niña jugando en el parque, de Raúl ( 7 años)

La conclusión que podemos sacar de este análisis se corresponde con la tendencia cultural de partida, en cuya base está la idea de reproducir la normatividad social, marcada por la normatividad atribuida al género. En esta línea, la ocupación del espacio por parte de los niños y niñas es otro de los enclaves observacionales en este primer bloque de la investigación. Dentro del marco de análisis, se ha observado cómo están distribuidas las zonas en el tiempo de recreo y qué lugar ocupan los niños y niñas en cada tipo de juego.

Ficha de observación del recreo

Fecha: 12 de junio Hora: 12:00-12:40

A la hora del recreo, los niños (Raúl, Fernando, Mario y Nicolae) juegan al pilla-pilla desplazándose por todo el patio pequeño, mientras que las niñas (Laura y Lourdes) juegan básicamente en la zona de los columpios. Pero de vez en cuando los chicos (sobre todo Raúl 
y Mario) se entretienen molestando a Laura y a Lourdes mientras estas se columpian, así que ellas se enfadan y se quejan por la actitud de ellos. En momentos breves, las chicas se suman a jugar al pilla-pilla.

Esta nota de la ficha de observación sirve de ejemplo para retratar la dinámica cotidiana de la ocupación del espacio durante el recreo en el periodo analizado. La norma solía ser que las niñas jugaban más en la periferia del recreo o en una zona concreta como, por ejemplo, los columpios, y los niños solían jugar más por todo el espacio de recreo y a juegos de mayor actividad física. Es cierto que la ocupación del espacio no puede considerarse una acción estereotipada por sí misma; sin embargo, la observación participante confirma una vez más lo examinado hasta el momento, existiendo una distribución del espacio desigual basada en la variable sexo. Esta distribución es desigualmente favorable para los niños que ocupan un mayor y central $\begin{array}{llll}\text { espacio frente las niñas. } & \text { las }\end{array}$

\subsection{Las narrativas de las actitudes sexistas}

La segunda parte de los análisis centra la atención en los relatos narrativos que visibilizan en mayor o menor medida las actitudes sexistas. Este tipo de actitudes son el resultado de la interiorización de los estereotipos de género propios de la cultura hegemónica y hacen referencia a pequeñas expresiones cotidianas que se concretan en actitudes de cuidado, gestos, acciones o palabras afectuosas dedicadas a los/as más pequeños/as, por parte de los niños y niñas mayores de 3 años. Por ejemplo, uno de los resultados más significativos del trabajo de campo es que de las personas que muestran más actitudes de cuidado -Lourdes, Laura y Fernando-, son a su vez las que tienen un familiar más pequeño dentro del aula (salvo en el caso de Lourdes). Por su parte, los que menos actitudes de cuidado han tenido fueron Carlos, Mario, Raúl y Nicolae, que no muestran evidencias de actitud de cuidado hacia otros/as (aun teniendo hermanos/as con ellos). Es decir en este grupo de niños y niñas son mayormente ellas quienes han mostrado actitudes de cuidado hacia los más pequeños, por el contrario, los niños generalmente han mostrado pocas actitudes paternales salvo en el caso de Fernando hacia su hermano menor.

En lo que respecta a las narrativas que evocan los estereotipos de género dentro del aula, se observan escenarios proyectivos tanto por parte de los adultos/as como de los pequeños/as. En una actividad programada, se leyeron dos cuentos no sexistas 
donde los alumnos/as atribuyeron mayoritariamente a las madres como las figuras encargadas de las tareas del hogar, como muestran las siguientes transcripciones de dos fichas de observación.

Ficha de observación de clase

\begin{tabular}{|l|l|l|}
\hline Fecha: 8 de junio & Hora: 17:00 - 17:50 & Maestras: Gema e Itziar \\
\hline Se realizó la lectura y el posterior comentario del cuento "El misterio del chocolate", \\
con Regina, Raúl, Mario, Carlos, Laura, Lourdes y Fernando. Un cuento que relata la historia \\
de una niña que siempre se encuentra en la nevera de su casa todos los alimentos que le \\
gustan, incluido el chocolate, y los que no tanto. Así se plantea el dilema de quiénes son las \\
personas que van a la compra y colocan cada cosa en su lugar. Después de la lectura del \\
cuento, se plantean algunas cuestiones sobre la colaboración en las tareas del hogar. \\
Las preguntas planteadas en "El misterio del chocolate" por la profesora y las \\
respuestas aportadas por el alumnado son las siguientes:
\end{tabular}

1. Cuando encuentras las cosas que te gustan en la cocina ¿quién las pone ahí? - A lo que todos y todas contestas que las colocan papá y mamá.

2. ¿Quién va a hacer la compra?

- Regina: Mamá... y papá. Y mamá y la abuela.

- Raúl: Abuela.

- Laura: Mamá, y a veces yo voy con ella.

- Mario y Fernando (hermanos): Mamá y abuela, y también nosotros.

- Lourdes: Papá y mamá. Unas veces papá, otras veces mamá, otras veces yo con mamá y la abuela...

- Carlos: Papá y mamá.

3. ¿Quién coloca la compra?

- Regina: Mamá y papá.

- Raúl: Papá y mamá (Raúl no vive con su madre, sino mayormente con su abuela, y también con su padre).

- Lourdes: Papá y mamá.

- Mario (hermano de Fernando): Papá y mamá.

- Fernando: No Mario, papá y mamá no. Mamá y yo, Mario nunca hace nada.

- Carlos: Papá y mamá.

- Laura: Mamá.

4. ¿Quién hace la comida?

- Regina: Mamá.

- Raúl: Mamá 
- Laura: Mamá.

- Mario y Fernando: Mamá, papá no hace nada.

- Yo: Y mientras mamá hace la comida, ¿papá qué hace?

- Fernando: Nada, tirado en el sofá viendo la tele.

- Mario: Papá siempre está en el sofá (dice su hermano entre risillas).

- Lourdes: Papá hace la comida.

5. ¿Quién pone y quita la mesa?

- Raúl: Abuela, yo no hago nada.

- Laura: Mamá siempre pone y quita la mesa y luego friega.

- Fernando: Pone y quita la mesa mamá, y no la ayudamos.

- Lourdes: Papá y mamá, y a veces yo también ayudo.

- Carlos: Mamá.

Ficha de observación de clase

\begin{tabular}{|l|l|l|}
\hline Fecha: 15 de junio & Hora: 17:00 - 17:30 & Maestra: Itziar \\
\hline jugar con muñecas". Cuenta la historia de un niño que nunca quería jugar con muñecas \\
porque pensaba que "esas cosas" eran sólo para su hermana pequeña. Una noche tiene \\
un sueño en el que la muñeca de su hermana se convierte en su amiga y se divierten \\
mucho juntos. Así, al amanecer, el niño ha cambiado de idea y desde entonces le tiene \\
un cariño especial a esa muñeca y juega con ella. Después de la lectura del cuento y \\
de sintetizar las ideas principales, se produjo la siguiente conversación: \\
- $\quad$ Itziar: ¿Entonces, los niños también juegan con muñecas? \\
- $\quad$ A lo que Raúl, Fernando y Mario contestan casi al unísono: iNo! \\
- $\quad$ Itziar: ¿Y por qué no?... ¿no acabamos de leer que tanto niños como niñas \\
- pueden jugar con muñecas? \\
Fernando (hermano de Mario): Pues Mario tiene una muñeca y juega con ella \\
- Mario (un poco alterado o avergonzado): iNo! \\
- Fernando: Sí, que yo te he visto. \\
- Mario: Que no, que yo no juego con ella. \\
- $\quad$ Fernando: iQue sí! \\
- Mario: iQue no!
\end{tabular}


El fragmento de esta segunda ficha muestra la dimensión sancionadora que tienen los estereotipos de género en nuestra cultura y, en este caso, para los niños que juegan con muñecas. En esta línea de análisis, se ha examinado también las implicaciones de los roles atribuidos por los pequeños/as según el género. Raúl entiende que las tareas de limpieza son propias del género femenino y muestra una tendencia hacia la cosificación de la figura de la mujer. Frases como: "esto ahora lo limpiáis vosotras" dirigiéndose a las maestras, o "así van las mujeres en verano, las mujercitas buenas, enseñando las tetas". En otras conversaciones se ponen de manifiesto que los niños y niñas de este centro no conciben la idea de que dos chicos puedan ser novios, diciendo incluso que les "da asco" (Fernando) o que "las mujeres no fuman" (Laura). Por último, rescataremos tres fragmentos del anecdotario que son reveladores de la normatividad de género asumida por los estudiantes del centro.

Regina: Soy una nena porque tenemos coleta [...] Los niños no tienen pelo.

\section{Anecdotario}

Fecha: 25 de junio

Luís se pone las chanclas de Andrea (rosas con un dibujo de una gata). Cuando Mario le ve dice: "Esas chanclas son de niñas".

- Itziar: ¿Por qué?

- Mario: Porque son rosas.

Fecha: 3 de julio

\section{Anecdotario}

Están sentadas/os en la mesa realizando una ficha y hablando:

- Raúl: Los niños siempre se tiran pedos.

- Laura (con tono de protesta): iY las niñas!

A modo de corolario, puede decirse que el presente análisis muestra los ambages de la realidad escolar en relación con los estereotipos y los prejuicios de género de nuestra cultura dominante. Desde diferentes fuentes de información se ha confirmado que existe una transferencia cultural de los estereotipos de género desde la etapa infantil que se materializa, tanto en la propia narrativa, como en las actitudes y juegos que realizan el alumnado. Estos análisis deben llevar a una reflexión profunda en la que se trabaje en una deconstrucción curricular de estos elementos, no sólo para alcanzar una situación más equilibrada entre hombres y mujeres, sino también para que las nuevas generaciones puedan entender la realidad social de una manera más enriquecedora. 


\section{CONCLUSIONES Y DISCUSIÓN}

En base a todo lo expuesto hasta el momento, concluiremos este apartado examinando el grado de cumplimiento que han tenido los objetivos de esta investigación. En relación con el primer objetivo específico referido a las preferencias de juego del alumnado, se encuentran diferencias entre niños y niñas, en concreto, ellas prefieren juegos estereotipados como femeninos y ellos los estereotipados como masculinos. Algunas de estas diferencias pueden encontrarse también en la investigación realizada por Henriques y De Jesus (2016) donde se constata que los niños y las niñas muestran preferencias diferentes por los juegos.

En lo que respecta a las actitudes de cuidado, se puede concluir también que las niñas mayores de 3 años muestran más actitudes maternales hacia los/las bebés que los niños. En la línea de los trabajos de Rodríguez et al (2004) que afirman que las chicas practican en los juegos un rol más romántico y maternal. De esta manera, se ven representadas las características que generalmente se le asocian a las mujeres: "ternura, intuición y colaboración" (ARTAL, 2009). En relación con el tercer objetivo, que versa sobre las relaciones que se establecen en los juegos, se observa cómo los niños mayores prefieren relacionarse con otros chicos y ellas prefieren relacionarse también entre chicas. Esta misma tendencia se observa en investigaciones realizadas por Rodríguez y Torio (2005) que afirman que a partir de los 4 años los grupos suelen hacerse más homogéneos según el sexo.

En cuanto a la preferencia por seleccionar dibujos estereotipados o neutros, se observa que las chicas prefieren personajes y dibujos estereotipados como femeninos y los chicos los prefieren estereotipados como masculinos. Henriques y De Jesus (2016) encontraron diferencias cromáticas donde los alumnos/as asocian el color azul a los niños y el color rosa a las niñas. Sumado a todos los estereotipos a los que están expuestos los niños y niñas, se suman los materiales lúdico-didácticos que les proporcionan, como bien fundamentan Cabrera y Martínez (2014) con los Doodles para niñas y los Doodles para niños, los cuales evidencian grandes diferencias entre los dibujos que se supone adecuados para niños y los que se suponen adecuados para niñas.

Además, se han identificado también numerosas narrativas sexistas dentro y fuera del aula donde se asignan a la mujer las labores de crianza y las tareas del hogar 
y se relaciona al hombre con el descanso, evidenciando así una transferencia cultural que merece ser analizada en posteriores investigaciones con mayor detenimiento. Los comentarios sexistas que se han datado son solo una pequeña parte que se exterioriza de todo un ideario complejo. Estas ideas que se expresan en forma de palabras han sido previamente adquiridas en cualquiera de los núcleos o sistemas con los que el individuo interactúa. Queda reflejado que desde muy pequeños/as se asignan diferentes papeles a las mujeres y a los hombres, tal como explica Sánchez-Castilla (2001), según los referentes maternos y paternos que tienen dentro del hogar (HENRIQUES Y DE JESUS, 2016).

Por último, se han podido apreciar diferencias en la ocupación del espacio físico durante el recreo, pues los chicos suelen ocupar toda la zona de recreo durante sus juegos, mientras que ellas prefieren la periferia o una zona concreta, como la zona de los columpios. Lo que vuelve a evocar los diferentes papeles sociales que se le atribuyen a mujeres y a hombres.

En definitiva, los análisis realizados sobre los tipos de juegos, los dibujos, las interacciones interpersonales, la ocupación del espacio, las actitudes de cuidado y las narrativas sexistas, concluyen que, existen evidencias suficientes para corroborar que existen diferencias significativas en materia de género entre los niños y las niñas de 3 a 7 años del centro de educación infantil Maracas. Los resultados de éstas y otras investigaciones sobre esta materia deben servir de base para re-significar el debate sobre las políticas educativas en materia de igualdad de género desde edades muy tempranas pues, como se ha podido constatar, la influencia y determinación cultural está muy presente condicionando el futuro de las nuevas generaciones.

\section{BIBLIOGRAFÍA}

ANDRADE, D.; ARBOLEDA, L. A. La movilización de la masculinidad como generadora de nuevas realidades. 2001. 216f. Trabajo de conclusión de curso (Psicología) - Facultad de Psicología de la Universidad de la Sabana, Chía, Colombia, 2001. Disponible en:

http://intellectum.unisabana.edu.co/bitstream/handle/10818/4066/131273.pdf?seque

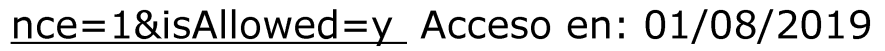

ARTAL, M. Construir el género: El cuestionamiento del sexismo y del androcentrismo en el sistema educativo. Acciones e Investigaciones Sociales, Zaragoza, v.27, p. 5-21, julio, 2009.

\section{BERICAT, E. La integración de los métodos cuantitativo y cualitativo en la}


investigación social. Barcelona: Ariel. 1998. 189 p.

BLANCO, N.; PIRELA, J. La complementariedad metodológica: Estrategia de integración de enfoques en la investigación social. Espacios Públicos, Venezuela, $v$. 19, n. 45, p. 97-111, abril, 2016.

BONILLA, A. Los roles de género. In: FERNÁNDEZ, J. (coord.), Género y sociedad. Madrid: Pirámide, 1998.

BOURDIEU, P.; PASSERON, J. C. La réproduction. París: Minuit, 1970.

BUTLER, J. El género en disputa: El feminismo y la subversión de la identidad. Traducción: M. A. Muñoz. Barcelona: Paidós, 2007, p. 316.

CABREARA, Y.; MARTÍNEZ, V. "Libros para niñas y libros para niños": Presencia de estereotipos de género en una colección de libros para dibujar. Cuestiones de género: de la igualdad y la diferencia, Valencia, v. 9, p. 184-217, marzo, 2014. Disponible en:

http://revpubli.unileon.es/index.php/cuestionesdegenero/article/view/1011/1026 Acceso en: 01/08/2019

CAPDEVILA, R. et al. La evaluación de la equidad de género en Educación Infantil: estudio paralelo en el Departamento de La Paz (Bolivia) y en la Comunidad Autónoma Catalana (España). Revista Iberoamericana de Evaluación Educativa, Bolivia $v$. 7, n.1, p. 63-77, abril, 2014. Disponible en:

https://repositorio.uam.es/bitstream/handle/10486/661826/RIEE 71 6.pdf?sequenc e=1\&isAllowed =y Acceso en: 01/08/2019

CARABAÑA, J.; DE ESPINOSA, E. L. La teoría social del interaccionismo simbólico: Análisis y valoración crítica. Revista española de investigaciones sociológicas, n.1, p. 159-203, 1978. Disponible en:

https://dialnet.unirioja.es/servlet/articulo?codigo=666889 Acceso en: 01/08/2019

CHANDÍA, F.; NAZAR, R.; OVIEDO, B. Comparación de la participación femenina en el mercado laboral trimestres enero-marzo 2011 y 2013. Horizontes Empresariales, Chillán, v. 13, n. 1, p. 24-43, 2014. Disponible en:

http://revistas.ubiobio.cl/index.php/HHEE/article/view/2111/1967 Acceso en: 01/08/2019

CONNELL, R. Educando a los muchachos: Nuevas investigaciones sobre masculinidad y estrategias de género para las escuelas. Traducción: Adriana Escobar. Nómadas, $n$. 14, p. 155-171, 2001. Disponible en:

https://www.redalyc.org/html/1051/105115268013/ Acceso en: 01/08/2019

DÍAZ, M. T. La perspectiva de género en la formación del profesorado de música.

Revista Electrónica Iberoamericana sobre Calidad, Eficacia y Cambio en

Educación, v. 3, n.1, p. 570-577, 2005. Disponible en:

https://repositorio.uam.es/bitstream/handle/10486/660907/REICE 31 54.pdf?seque

$\underline{\text { nce }=1 \text { \&isAllowed }=y}$ Acceso en: 01/08/2019

ESPAÑA. Decreto 4/2008, de 11 de enero, por el que se aprueba el Currículo de

Educación Infantil para la Comunidad Autónoma de Extremadura. DOE: Diario Oficial 
de Extremadura, Madrid, n. 12, p. 1226-1272, 18 de enero de 2008. Disponible en: http://doe.juntaex.es/pdfs/doe/2008/120o/08040004.pdf Acceso en: 29 jul. 2019

ESPAÑA. Ley Orgánica 2/2006, de 3 de mayo de 2006, de Educación. BOE: Boletín Oficial del Estado, Madrid, n. 106, p. 17158-17207, 4 de mayo de 2006. Disponible en: http://www.boe.es/boe/dias/2006/05/04/pdfs/A17158-17207.pdf Acceso en: 29 jul. 2019

ESPAÑA. Ley Orgánica 8/2013, de 9 de diciembre de 2013, para la mejora de la calidad educativa. BOE: Boletín Oficial del Estado, Madrid, n. 295, p. 97858-97921, 10 de diciembre de 2013. Disponible en:

https://www.boe.es/diario boe/txt.php?id=BOE-A-2013-12886 Acceso en: 29 jul. 2019

ESPAÑA. Real Decreto 1630/2006, n.4, de 29 de diciembre de 2006, por el que se establecen las enseñanzas mínimas del segundo ciclo de Educación Infantil. BOE: Boletín Oficial del Estado, Madrid, n. 4, p. 474-482, 2007, 4 de enero de 2007. Disponible en: https://www.boe.es/boe/dias/2007/01/04/pdfs/A00474-00482.pdf Acceso en: 29 jul. 2019

FAUSTO-STERLING, A. Cuerpos sexuados: La política de género en la construcción de la sexualidad. Traducción: Ambrosio García Leal. Barcelona: Editorial Melusina, S. L, 2006. 263 p.

FONSECA, C.; QUINTERO, M. L. La Teoría Queer: la de-construcción de las sexualidades periféricas. Sociología, v. 24, n, 69, p. 43-60, 2009. Disponible en: http://www.scielo.org.mx/pdf/soc/v24n69/v24n69a3.pdf Acceso en: 01/08/2019

FRÍAS-ARMENTA, M.; LÓPEZ-ESCOBAR, A. E.; DÍAZ-MÉNDEZ, S. G. Predictores de la conducta antisocial juvenil: un modelo ecológico. Estudios de Psicología (Natal), México v. 8, n. 1, p. 15-24, 2003. Disponible en:

http://www.scielo.br/scielo.php?pid=S1413$\underline{294 X 2003000100003 \& s c r i p t=s c i}$ arttext\&tIng=es Acceso en: 01/08/2019

GARCÍA-LEIVA, P. Identidad de género: Modelos explicativos. Escritos de psicología, Huelva, v. 7, p. 71-81, 2005.

GARCÍA PERALES, R. La educación desde la perspectiva de género. Ensayos, v. 27, p. $1-18,2012$.

GIROUX, H. Teorías de la reproducción y la resistencia en la nueva sociología de la educación: un análisis crítico. Cuadernos Políticos, Colombia, n. 44, p. 36-65, enero, 1985. Disponible en:

http://revistas.pedagogica.edu.co/index.php/RCE/article/view/5140/4214 Acceso en: 01/08/2019

GROS, A. Judith Butler y Beatriz Preciado: una comparación de dos modelos teóricos de la construcción de la identidad de género en la teoría Queer. Revista Civilizar Ciencias Sociales y Humanas, Bogotá, v. 16, n. 30, p. 245-260, junio, 2016. Disponible en: http://www.scielo.org.co/pdf/ccso/v16n30/v16n30a18.pdf Acceso en: 01/08/2019 
HENRIQUES, H.; DE JESUS, A. Educação para a igualdade de género: leituras a partir da realidade de cinco jardins de infância do distrito de Portalegre, Portugal. Foro de Educación, v. 14, n. 20, p. 339-360, junio, 2016. Disponible en:

http://dx.doi.org/10.14516/fde.2016.014.020.017 Acceso en: 01/08/2019

JAYME, M. La identidad de género. Revista de psicoterapia, v. 10, n. 40, p. 5-22, 1999.

LAMAS, M. Diferencias de sexo, género y diferencia sexual. Cuicuilco, México, v. 7, n.18, abril, 2000. Disponible en: http://www.redalyc.org/pdf/351/35101807.pdf Acceso en: 01/08/2019

MARTÍNEZ, J. L. et al. Educación sexual y formación del profesorado en España: diferencias por sexo, edad, etapa educativa y comunidad autónoma. Magister: Revista miscelánea de investigación, n. 24, p. 37-47, junio, 2011. Disponible en: https://dialnet.unirioja.es/servlet/articulo?codigo=3844427 Acceso en: 01/08/2019

MARTÍNEZ, V. I. Interaccionismo simbólico y la necesidad de comprendernos. In: MARTÍNEZ, V. I. Simbología de la violencia verbal. Maracaibo, Venezuela: Inver-EGroup Venezuela C. A, 2015, p. 11-42.

MARTÍNEZ, M. B., et al. Legitimación de la violencia en la infancia: un abordaje desde el enfoque ecológico de Bronfenbrenner. Psicología desde el Caribe. Universidad del Norte, v. 31, n. 1, p. 133-160, abril, 2014. Disponible en: http://rcientificas.uninorte.edu.co/index.php/psicologia/article/view/4930 Acceso en: 01/08/2019

MAGALLÓN. C. Los conflictos armados desde los roles e identidades de género. In: SALAMANCA, M. E. (coord) Las prácticas de la resolución de conflictos en América Latina. Universidad de Deusto. Bilbao: Publicaciones de la universidad de Deusto, 2008, vol. 15, p. 73-82.

OKUDA, M.; GÓMEZ-RESTREPO, C. Métodos de investigación cualitativa:

triangulación. Revista colombiana de psiquiatría, Bogotá, v. 34, n. 1, p. 118-124, 2005. Disponible en: http://www.redalyc.org:9081/articulo.oa?id=80628403009 Acceso en: 01/08/2019

PLA, I. ; ADAM, A.; BERNABEU, I. Estereotipos y prejuicios de género: factores determinantes en salud mental. Norte de salud mental, v. 11, n. 46, p. 20-28, 2013. Disponible en: https://dialnet.unirioja.es/servlet/articulo?codigo $=4694952$ Acceso en: 01/08/2019

ROCHA-SÁNCHEZ, T. E. DÍAZ-LOVING, R. Cultura de género: La brecha ideológica entre hombres y mujeres. Anales de psicología, Murcia, v. 21, n. 1, p. 42-49, junio, 2005. Disponible en: https://revistas.um.es/analesps/article/view/27111/26301 Acceso en: 01/08/2019

RODRÍGUEZ, M. A.; HERNÁNDEZ, J.; PEÑA, J. V. Pensamiento docente sobre el juego en educación infantil: análisis desde una perspectiva de género. Revista española de pedagogía, La Rioja, v. 299, p. 455-466, diciembre, 2004. Disponible en: https://www.jstor.org/stable/23765068 Acceso en: 01/08/2019 
RODRÍGUEZ, M. C.; TORIO, S. El discurso de género del profesorado de educación infantil: hablando acerca de la ética del cuidado. Revista Complutense de Educación, v. 16, n. 2, p. 471-487, 2005.

SÁNCHEZ, V. Estereotipos de género: Un estudio en el ámbito rural de Salamanca. 2011. 124f. Disertación (Maestrado en Estudios Interdisciplinares de Género) Facultad de Derecho de la Universidad de Salamanca, Salamanca, España, 2011.

TOLDOS, P. M. Adolescencia, violencia y género. 2002. 519f. Disertación (Doctorado en Psicología evolutiva y de la educación) - Facultad de Psicología de la Universidad Complutense de Madrid, Madrid, España, 2002.

VALLES, M. S. Técnicas cualitativas de investigación social. Madrid: Editorial Síntesis, S. A. 1999. 430p.

WEEKS, Jeffrey. WEEKS, Jeffrey. La invención de la sexualidad. Sexualidad. Barcelona: Paidós Ibérica, p. 55-87, 1998.

\title{
NOTAS
}

\section{ESTEREOTIPOS DE GÉNERO EN EDUCACIÓN INFANTIL: UN ESTUDIO DE CASO DESDE LA PERSPECTIVA SOCIOCULTURAL}

\author{
Itziar García-Prieto \\ MSc Investigación Educativa \\ Universidad de Extremadura, Cáceres, España \\ igprieto@unex.es \\ https://orcid.org/0000-0001-8990-7829 \\ Rubén Arriazu-Muñoz \\ PhD Sociología de la Educación \\ Universidad de Extremadura, Cáceres, España \\ rarriazu@unex.es \\ https://orcid.org/0000-0001-6721-6023 (0)
}

Endereço de correspondência do principal autor

Rubén Arriazu-Muñoz. Universidad de Extremadura. Facultad de Formación del Profesorado. Avenida de la Universidad s/n, 10004, Cáceres, España.

\section{AGRADECIMENTOS}

Agradecemos as contribuições feitas pelos revisores da revista para melhorar o artigo.

\section{CONTRIBUIÇÃO DE AUTORIA}

Concepção e elaboração do manuscrito: I.G-P y R.A-M

Coleta de dados: I.G-P

Análise de dados: I.G-P y R.A-M

Discussão dos resultados: I.G-P y R.A-M

Revisão e aprovação: I.G-P y R.A-M

\section{CONJUNTO DE DADOS DE PESQUISA}

Todo o conjunto de dados que dá suporte aos resultados deste estudo foi publicado no próprio artigo.

\section{FINANCIAMENTO}


Não se aplica.

CONSENTIMENTO DE USO DE IMAGEM

Não se aplica.

APROVAÇÃo DE COMITÊ DE ÉTICA EM PESQUISA

Não se aplica.

CONFLITO DE INTERESSES

Não se aplica.

LICENÇA DE USO - uso exclusivo da revista

Os autores cedem à Zero-a-Seis os direitos exclusivos de primeira publicação, com o trabalho simultaneamente licenciado sob a Licença Creative Commons Attribution (CC BY) 4.0 International. Esta licença permite que terceiros remixem, adaptem e criem a partir do trabalho publicado, atribuindo o devido crédito de autoria e publicação inicial neste periódico. Os autores têm autorização para assumir contratos adicionais separadamente, para distribuição não exclusiva da versão do trabalho publicada neste periódico (ex.: publicar em repositório institucional, em site pessoal, publicar uma tradução, ou como capítulo de livro), com reconhecimento de autoria e publicação inicial neste periódico.

PUBLISHER - uso exclusivo da revista

Universidade Federal de Santa Catarina. Núcleo de Estudos e Pesquisas da Educação na Pequena Infância - NUPEIN/CED/UFSC. Publicação no Portal de Periódicos UFSC. As ideias expressadas neste artigo são de responsabilidade de seus autores, não representando, necessariamente, a opinião dos editores ou da universidade.

EDITORES - uso exclusivo da revista

Márcia Buss-Simão e Kátia Agostinho.

HISTÓRICO - uso exclusivo da revista

Recebido em: 25-04-2019 - Aprovado em: 05-09-2019 